\title{
Optimizing the operation of the Qingshitan Reservoir in the Lijiang River for multiple human interests and quasi-natural flow maintenance
}

\author{
Qiuwen Chen ${ }^{1,2, *}$, Duan Chen ${ }^{1,3}$, Ruiguang $\mathrm{Han}^{5}$, Ruonan $\mathrm{Li}^{1}$, Jinfeng Ma ${ }^{1}$, Koen Blanckaert ${ }^{1,4}$ \\ 1. Research Center for Eco-Environmental Sciences, Chinese Academy of Sciences, Beijing 100085, China \\ 2. Three Gorges University, Yichang 443002, China \\ 3. Changjiang River Scientific Research Institute, Wuhan 430010, China \\ 4. Laboratory of Hydraulic Constructions, School of Architecture, Civil and Environment Engineering, Lausanne, Switzerland \\ 5. Haihe Water Conservancy Commission, Tianjin 300170, China
}

Received 14 January 2012; revised 29 June 2012; accepted 03 July 2012

\begin{abstract}
For reservoir operation, maintaining a quasi-natural flow regime can benefit river ecosystems, but may sacrifice human interests. This study took the Qingshitan Reservoir in the Lijiang River as a case, and developed an optimization model to explore a trade-off solution between social-economic interests and nature flow maintenance on a monthly base. The objective function considered irrigation, cruise navigation and water supply aspects. An index of flow alteration degree was proposed to measure the difference between the regulated discharge and the natural flow. The index was then used as an additional constraint in the model besides the conventional constraints on reservoir safety. During model solving, different criteria were applied to the index, representing various degrees of alteration of the natural flow regime in the river. Through the model, a relationship between social-economic interests and flow alteration degree was established. Finally, a trade-off solution of the reservoir operation was defined that led to a favorable social-economic benefit at an acceptable alteration of the natural flow.
\end{abstract}

Key words: reservoir operation; optimization model; flow alteration; trade-off solution

DOI: $10.1016 /$ S1001-0742(11)61029-2

\section{Introduction}

River ecosystems are known to depend strongly on the flow regime (Whiting, 2002; Tomlinson and de Carlo, 2003; Petts, 2009). Conventional reservoir operations have focused on the maximization of social-economic benefits and paid little attention to ecosystem requirements (Smith et al., 2007). River flow in the downstream reach of reservoirs was largely reduced or the pattern was severely altered, thus the structure and functions of river ecosystems were damaged (Acreman, 2000). Following the increasing awareness of river ecosystem protection, the importance of maintaining a quasi-natural flow in the stream to meet the requirements of the biota has gradually reached a consensus in the context of sustainable river development.

Relevant research has been carried out in the past decades on considering the in-stream flow requirements in conventional reservoir operations (Cardwell et al. 1996; Labadie, 2004; Castelletti et al., 2008). Homa et al. (2005) summarized that most of the studies proposed to release a minimum constant flow in reservoir operation to assure the basic requirements of stream ecosystems. Cardwell et al. (1996) presented a model with focus on protecting various typical fish and derived 12 different optimal policies on

\footnotetext{
* Corresponding author. E-mail: qchen@rcees.ac.cn
}

minimum flow release. However, Richter et al. (1996, 1997) and Smith et al. (2007) argued that ecological flow should be time-varying because of hydrological seasonality and species life stage, thus they proposed a concept of 'range of alteration (RA)' to evaluate the impacts of hydraulic structures on natural flow regimes.

Homa et al. (2005) defined a concept "eco-deficit" to assess human impacts on natural flow by measuring the area between unregulated and regulated hydrographs and proposed a framework to balance human demands and river ecosystem health. Suen and Eheart (2006) used the Taiwan Eco-hydrology Indicator System to define an ecological flow regime and applied a non-dominatedsorting genetic algorithm to find the Pareto-optimal set of operating rules that compromised between human needs and river ecosystem conservation. However, it is difficult and subjective in this approach to assign weights to the different objectives, especially when they are conflicting. In addition, the approach introduced about 32 parameters, which increased model complexity and uncertainty. Recently, Chen et al. (2010) and Li et al. (2011a) employed an ecological hydrograph representing the daily flow requirement for conserving the habitat of the target fish and used it as a constraint in the operation model. These methods mainly aim at a very limited number of species, but ignore 
the holistic ecosystem.

Following the increasing concerns about the integrity of aquatic ecosystems, this research developed an innovative approach which focused on maintaining a quasi-natural flow regime in the river. In addition, the method used the index of alteration degree as a constraint in the optimization model instead of as an objective. This transformed a multi-objective problem into a single-objective problem so as to avoid the subjective weight assignment. The study took the Lijiang River whose flow regime is largely regulated by upstream reservoirs as the case and explored optimal operation schemes to balance the different human interests and natural flow maintenance. The results indicate that the proposed approach is promising in adaptive reservoir operations.

\section{Description of study case}

The study case is the Qingshitan Reservoir in the upstream tributary of the Lijiang River (Fig. 1), which is mainly situated in the Guangxi Province of southwest China. The Lijiang River is a world famous scenic place with a marvelous karst landscape. The river basin has a high precipitation with an annual average of $1980 \mathrm{~mm}$ (Li et al., 2011b). However, due to the special topographic features and the strong seasonality of rainfall, the discharges in

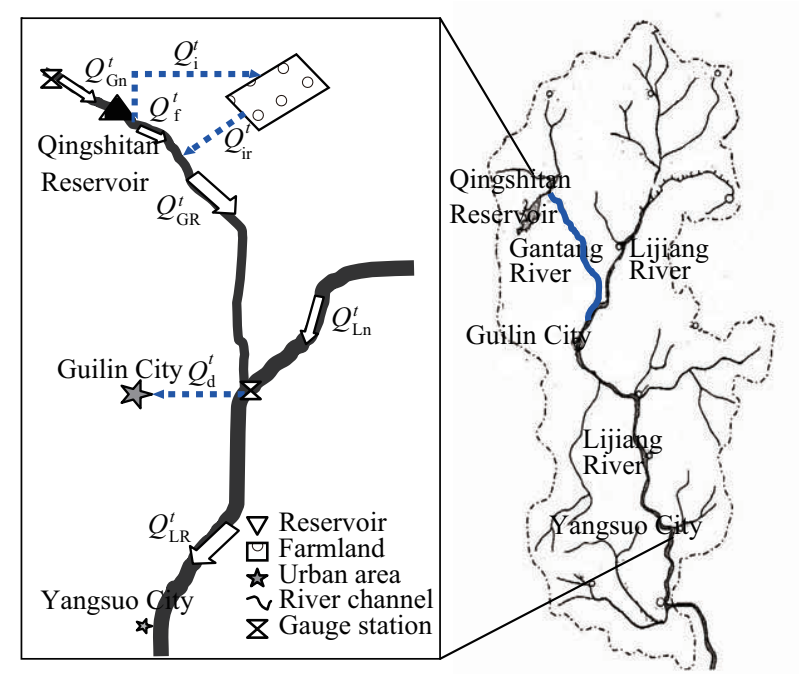

Fig. 1 Research area and sketch of the operation process of the Qingshitan Reservoir. The meaning of each $Q$ in the figure is given in Eqs. (1) and (2). the river have significant seasonal variation ( $\mathrm{Li}$ et al., 2010; Ye et al., 2010). Analyses of the hydrological data (1958-2009) from the Yangshuo station show that the daily discharges vary from 12 to $12000 \mathrm{~m}^{3} / \mathrm{sec}$ with an average of $120 \mathrm{~m}^{3} / \mathrm{sec}$. The average discharge in the dry season, which is from middle October to early March, is $15 \mathrm{~m}^{3} / \mathrm{sec}$, and the recorded minimum flow is $3.8 \mathrm{~m}^{3} / \mathrm{sec}$ ( $\mathrm{Li}$ et al., 2011b)

The low flow in the dry season poses great threats to the local water supply and aquatic ecosystem (Fig. 2). In addition, tourism is the predominant income of the local economy. When the discharge in the middle reach (gauged at the Guilin station) is lower than $30 \mathrm{~m}^{3} / \mathrm{sec}$, tourist cruises are suspended ( $\mathrm{Li}$ et al., 2011b), which seriously impacts the local economy. Therefore, a series of reservoirs have been or will be constructed in the main stream and tributaries of the river. The Qingshitan Reservoir, located in the Gantang River, is presently in operation.

The Qingshitan Reservoir has a capacity of $3.70 \times 10^{8}$ $\mathrm{m}^{3}$, and the detailed properties of the reservoir are as follows: annual regulation; reservoir capacity $\left(V_{\mathrm{m}}\right) 4.2 \times 10^{8}$ $\mathrm{m}^{3}$, dead storage $\left(V_{\mathrm{d}}\right) 0.5 \times 10^{8} \mathrm{~m}^{3}$, normal high water level $225 \mathrm{~m}$, dead water level $204 \mathrm{~m}$, and maximum release through turbine $337 \mathrm{~m}^{3} / \mathrm{sec}$. The major functions include agricultural irrigation water supply and water recharge to downstream for navigation and ecological flow demand during the dry season. The designed discharge for irrigation is $13.5 \mathrm{~m}^{3} / \mathrm{sec}$, and the expected flow for navigation and ecological demand is $30.0 \mathrm{~m}^{3} / \mathrm{sec}$ in the middle reach (Li et al., 2011b). In addition, the domestic water supply to Guilin City is $10 \mathrm{~m}^{3} / \mathrm{sec}$ (Fig. 1).

The operations of the Qingshitan Reservoir are illustrated in Fig. 1, where the natural inflow from the Gantang River $\left(Q_{\mathrm{Gn}}^{t}, \mathrm{~m}^{3} / \mathrm{sec}\right)$ to the reservoir is routed by the spillway and the irrigation channel. Water is diverted to the farmland $\left(Q^{t}, \mathrm{~m}^{3} / \mathrm{sec}\right)$ for irrigation, and part of this $\left(Q_{\text {ir }}^{t}, \mathrm{~m}^{3} / \mathrm{sec}\right)$ drains back to the Gangtang River. When the inflow exceeds the reservoir capacity, extra water is released $\left(Q_{\mathrm{f}}^{t}, \mathrm{~m}^{3} / \mathrm{sec}\right)$ to downstream through the spillway. The flow in the Gangtang River $\left(Q_{\mathrm{GR}}^{t}, \mathrm{~m}^{3} / \mathrm{sec}\right)$ joins with the Lijiang River at Guilin City, where water is taken $\left(Q_{\mathrm{d}}^{t}\right.$, $\mathrm{m}^{3} / \mathrm{sec}$ ) for domestic supply.

The previous operations of the Qingshitan Reservoir were predominately oriented toward the maximization of human benefits, which has caused significant changes to the downstream flow regime and thus the ecosystem $(\mathrm{Li}$
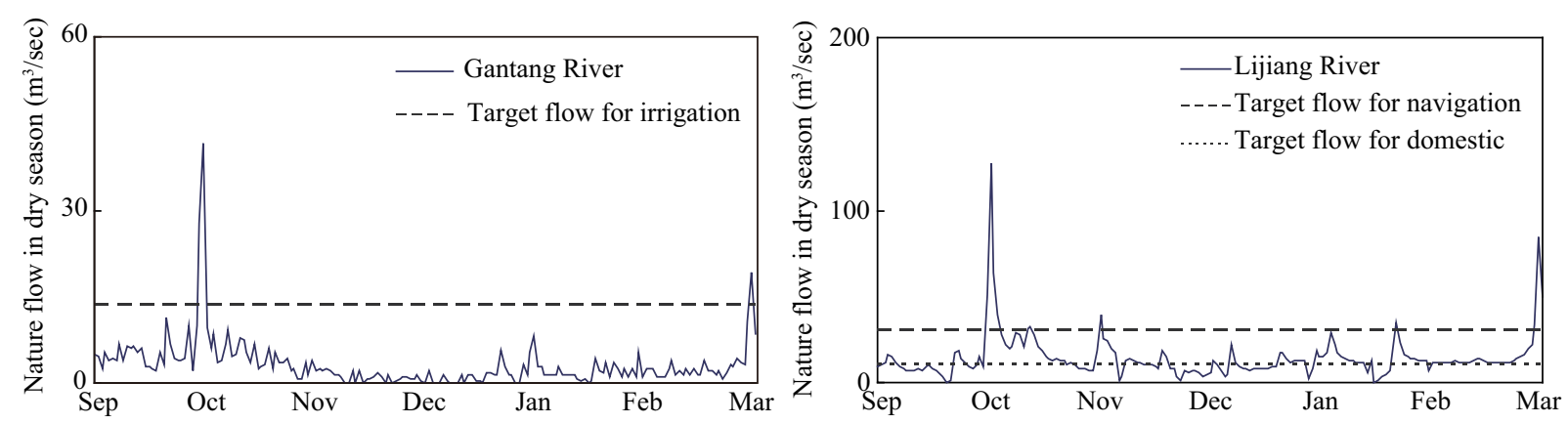

Fig. 2 Natural flow in the Gantang River and the Lijiang River during dry season, together with target flow for irrigation, domestic water supply and navigation. 
et al., 2010, 2011b; Ye et al., 2010; Chen et al., 2011). Following the increasing awareness of river conservation, the operations should be adapted to take into account the ecosystem requirements.

\section{Optimization model development}

The study developed a model to explore an optimal operation scheme for the Qingshitan Reservoir that can mostly meet the multiple human interests at an acceptable flow alteration. It is a monthly model, and in particular it pays special attention to the constraint of maintaining a quasinatural flow in the downstream.

\subsection{Objective function}

The reservoir provides service for irrigation, domestic water supply and water recharge in the dry season for navigation, thus the objective function can be written as:

$S_{\mathrm{h}}=\max \left(\frac{1}{12} \sum_{t=1}^{12}\left(w_{1} \cdot \frac{Q_{\mathrm{i}}^{t}}{Q_{\mathrm{ig}}}+w_{2} \cdot \frac{Q_{\mathrm{GR}}^{t}+Q_{\mathrm{Ln}}^{t}}{Q_{\mathrm{d}}}+w_{3} \cdot \frac{Q_{\mathrm{GR}}^{t}+Q_{\mathrm{Ln}}^{t}-Q_{\mathrm{d}}^{t}}{Q_{\text {naiv }}}\right)\right)$

where, $S_{\mathrm{h}}$ is the overall degree of satisfaction of human interests. The notation $t$ denotes the month of the year; $w_{1}$, $w_{2}$ and $w_{3}$ are the weights of the satisfaction degree for irrigation, water supply and navigation, respectively. According to the 'Handbook of Qingshitan Reservoir', these services were equally important; therefore, all the weights were given a value of $1 / 3 . Q_{\text {ig }}\left(\mathrm{m}^{3} / \mathrm{sec}\right), Q_{\mathrm{d}}\left(\mathrm{m}^{3} / \mathrm{sec}\right)$ and $Q_{\text {naiv }}\left(\mathrm{m}^{3} / \mathrm{sec}\right)$ are the target discharge for irrigation, water supply and navigation, respectively. As illustrated in Fig. 1, $Q_{\mathrm{i}}^{t}\left(\mathrm{~m}^{3} / \mathrm{sec}\right)$ is the discharge for irrigation in the $t$ month; $Q_{\mathrm{GR}}^{t}\left(\mathrm{~m}^{3} / \mathrm{sec}\right)$ is the regulated flow in the $t$ month in the Gangtang River, which is given by $Q_{\mathrm{f}}^{t}+Q^{t}{ }_{\text {ir }} ; Q^{t}{ }_{\text {ir }}\left(\mathrm{m}^{3} / \mathrm{sec}\right)$ is the returned water from irrigation, which was $17.8 \%$ of $Q^{t}{ }_{\mathrm{i}}\left(\mathrm{m}^{3} / \mathrm{sec}\right)$ in the study case (Guangxi Water Resources Bureau, 1984); $Q_{\mathrm{Ln}}^{t}\left(\mathrm{~m}^{3} / \mathrm{sec}\right)$ is the natural flow in the $t$ month in the Lijiang River; $Q^{t}{ }_{\mathrm{d}}\left(\mathrm{m}^{3} / \mathrm{sec}\right)$ is the discharge supplied to Guiling City in the $t$ month. It is noted that the satisfaction degree for navigation is zero if the real discharge in the channel is less than the minimum flow requirement for navigation

\subsection{Constraints}

The mass conservation of the reservoir in discrete form is written as:

$V^{t+1}-V^{t}=\left(Q_{\mathrm{Gn}}^{t}-Q_{\mathrm{f}}^{t}-Q_{\mathrm{i}}^{t}\right) \times T, \quad t=1,2 \ldots, 12$

where, $V^{t}\left(\mathrm{~m}^{3}\right)$ and $V^{t+1}\left(\mathrm{~m}^{3}\right)$ are reservoir storage in the $t$ month and $t+1$ month, respectively; $T$ (sec) is the operational time in $t$ month. $Q_{\mathrm{Gn}}^{t}\left(\mathrm{~m}^{3} / \mathrm{sec}\right)$ is the natural flow into the reservoir in the $t$ month; $Q_{\mathrm{f}}^{t}\left(\mathrm{~m}^{3} / \mathrm{sec}\right)$ is the direct discharge from the reservoir to the downstream. There is no tributary between the Gantang River and the Lijiang River, and the bottom leakage and surface evaporation loss was not considered in the model.

The water storage of the reservoirs should always be bounded by the dead storage $V_{\mathrm{d}}\left(\mathrm{m}^{3}\right)$ and the reservoir capacity $V_{\mathrm{m}}\left(\mathrm{m}^{3}\right)$ :

$V_{\mathrm{d}} \leqslant V^{t} \leqslant V_{\mathrm{m}}$
Correspondingly, the reservoir water level is restrained by the dead water level $H_{\mathrm{d}}(\mathrm{m})$ and the maximal water level $H_{\mathrm{m}}(\mathrm{m})$.

$H_{\mathrm{d}} \leqslant H^{t} \leqslant H_{\mathrm{m}}$

The release of the reservoir in the $t$ month (noted as $Q_{\mathrm{f}}^{t}$ ) should never exceed the maximum capacity $\left(Q_{\max }\right)$ of the reservoir and should not be negative.

$0 \leqslant Q_{\mathrm{f}}^{t} \leqslant Q_{\max }$

Previous studies mostly incorporate a constant minimum flow (Labadie, 2004; Homa et al., 2005) for river ecosystem protection in reservoir operations. Such treatment has recently been seriously criticized because the in-stream flow requirements are far more complex than a constant base flow (Richter et al., 1996, 1997; Smith et al., 2007). Some researchers proposed a constraint of an ecological hydrograph, which is usually a time-varying flow requirement of a specific species. To offer a holistic protection of the ecosystem, this research focuses on maintaining a quasi-natural flow in the river channel.

The difference between the regulated flow and the natural flow were compared for each month. To emphasize important seasons such as the fish spawning period (Li et al., 2011a), a weight is assigned to each month. The overall flow alteration is the sum of the weighted flow disturbances of each month.

$w_{\mathrm{G}}^{t}=\frac{\frac{\left|Q_{\mathrm{Gn}}^{t}-Q_{\mathrm{GR}}^{t}\right|}{Q_{\mathrm{Gn}}^{t}}}{\sum_{t=1}^{12} \frac{\left|Q_{\mathrm{Gn}}^{t}-Q_{\mathrm{GR}}^{t}\right|}{Q_{\mathrm{Gn}}^{t}}}$

$w_{\mathrm{L}}^{t}=\frac{\frac{\left|Q_{\mathrm{Ln}}^{t}-Q_{\mathrm{LR}}^{t}\right|}{Q_{\mathrm{Ln}}^{t}}}{\sum_{t=1}^{12} \frac{\left|Q_{\mathrm{Ln}}^{t}-Q_{\mathrm{LR}}^{t}\right|}{Q_{\mathrm{Ln}}^{t}}}$

$D_{\mathrm{G}}=\sum_{t=1}^{12} w_{\mathrm{G}}^{t} \times \frac{\left|Q_{\mathrm{Gn}}^{t}-Q_{\mathrm{GR}}^{t}\right|}{Q_{\mathrm{Gn}}^{t}} \times 100 \%$

$D_{\mathrm{L}}=\sum_{t=1}^{12} w_{\mathrm{L}}^{t} \frac{\left|Q_{\mathrm{Ln}}^{t}-Q_{\mathrm{LR}}^{t}\right|}{Q_{\mathrm{Ln}}^{t}} \times 100 \%$

where, $D_{\mathrm{G}}$ and $D_{\mathrm{L}}$ are the overall flow alteration degree in the Gantang River and the Lijiang River, respectively; $w_{\mathrm{G}}^{t}$ and $w_{\mathrm{L}}^{t}$ are the weights of $D_{\mathrm{G}}$ and $D_{\mathrm{L}}$ in the $t$ month; $Q_{\mathrm{LR}}^{t}$ is the regulated flow in the $t$ month in Lijiang River.

To allow a certain degree of flow alteration, a slack variable $\mu(\%)$ was introduced as a dynamic constraint in the optimization model. It is written as:

$D_{\mathrm{G}} \leqslant \mu_{\mathrm{GR}}$

$D_{\mathrm{L}} \leqslant \mu_{\mathrm{LR}}$

where, $\mu_{\mathrm{GR}}$ and $\mu_{\mathrm{LR}}$ are the allowed degree of flow disturbance in the Gantang River and the Lijiang River, respectively. These two constraints were used to address the aspect of quasi-natural flow maintenance. 
The reservoir is operated by controlling the discharges. Since the operations are monthly-based, the variables to be optimized were $\left[Q_{\mathrm{f}}^{1}, Q^{2}{ }_{\mathrm{f}}, \ldots, Q^{12}{ }_{\mathrm{f}}\right]$ for water recharge and $\left[Q^{1}{ }_{\mathrm{i}}, Q^{2}{ }_{\mathrm{i}}, \ldots, Q^{12}{ }_{\mathrm{i}}\right]$ for irrigation.

\subsection{Model solving by genetic algorithm}

There are plenty of techniques for solving reservoir optimization models, including linear programming, dynamic programming, genetic algorithm, gradient-based searching and heuristic programming (Yeh, 1985; Wurbs, 1996; Labadie, 2004; Hakimi-Asiabar et al., 2010). The genetic algorithm (GA), first conceived by John Holland (1975), has been highlighted by many researchers for its capability in solving problem with discontinuous, combinatorial and nonlinear objective functions or non-differentiable and non-convex design spaces (Shaffer, 1984; Goldberg, 1989; Labadie, 2004). It has demonstrated special advantages in reservoir management (Chang and Chen, 1998; Cai et al., 2001), reservoir operating rules (Oliveira and Loucks, 1997), real-time reservoir operation (Akter and Simonovic, 2004) and multi-reservoir optimization (Sharif and Wardlaw, 2000). In this study, GA was adopted to explore practical solutions of the optimization model.

To improve the performance of solution seeking, a GA with an adaptive mutation operator and crossover operator (Srinivas and Patnaik, 1994) was employed in the study. The population size was 5000 and the iteration was set 500 generations. The procedure stopped when the maximum number of allowed generations was reached or a solution whose objective value and the averaged objective value has a difference within $10^{-6}$ was found.

The modelling of the hydrological routine in the studied river reach under reservoir operation has been fully validated using the observed data at Guilin station (Li et al., $2008,2011 b)$. The capability of the proposed GA method has been well tested in the optimization of two cascaded reservoirs in the Yalong River (Chen et al., 2012).

\section{Results}

The proposed approach was used to optimize the Qingshitan Reservoir operations in a typical normal-flow year for demonstrating its applicability.

Two scenarios were first analyzed for references that are: (1) without the constraint of flow alteration; and (2) with the constraint of full natural flow. For reference (1), the constraint of flow alteration was excluded and the operation schemes with maximum degree of satisfaction for human interests were obtained. The flow alteration degrees of the Gangtang River and the Lijiang River were then calculated under the obtained operations. For reference (2), the allowed flow alteration $\mu_{\mathrm{GR}}$ and $\mu_{\mathrm{LR}}$ were set to zero, and the operation schemes with possible maximum degree of satisfaction for human interests were obtained. The results of the two references are shown in Table 1.

To balance the human interest and ecological conservation, and to seek for possible trade-offs, a series of operation scenarios were investigated by assigning the
Table 1 Comparison of $S_{\mathrm{h}}$ and $D_{\mathrm{f}}$ of the two reference situations in typical even year

\begin{tabular}{lll}
\hline Index & Reference (1) & Reference (2) \\
\hline$S_{\mathrm{h}}$ & $91 \%$ & $19.4 \%$ \\
$D_{\mathrm{G}}$ & $900 \%$ & $0.0 \%$ \\
$D_{\mathrm{L}}$ & $75 \%$ & $0.0 \%$ \\
\hline
\end{tabular}

slack variables $\mu_{\mathrm{GR}}$ and $\mu_{\mathrm{LR}}$ different values in the range of $(0,900 \%)$ and $(0,75 \%)$, respectively. Since there is no reservoir in the main stream, the alteration of the natural flow in the Lijiang River is dependent on that of the Gantang River. Therefore, the alteration degree in the Gantang River $\left(\mu_{\mathrm{GR}}\right)$ was selected as the major variable for investigation. In this research, $\mu_{\mathrm{GR}}$ was changed from $0 \%$ to $900 \%$ with an increment of $20 \%$. To study the impact of $\mu_{\mathrm{GR}}$ on $D_{\mathrm{L}}$, the allowed alteration degree in the Lijiang River $\left(\mu_{\mathrm{LR}}\right)$ was fixed at $75 \%$, which was the maximum disturbance degree identified above. Under such a configuration, 45 scenarios in total were investigated (see Table 1). For each scenario, a value was assigned to $\mu_{\mathrm{GR}}$ and $\mu_{\mathrm{LR}}$ was kept at $75 \%$, then the flow alteration constraint was imposed in the optimization model. The reservoir operation schemes of different flow alteration degrees were derived through GA and the corresponding degrees of satisfaction of human interests $\left(S_{\mathrm{h}}\right)$ were calculated. Meanwhile, the real alteration degrees $\left(D_{\mathrm{G}}\right.$ and $\left.D_{\mathrm{L}}\right)$ of each operation scheme were calculated by Eqs. (8) and (9). The relationship between human interests and flow alterations was then established, as given in Fig. 3.

Figure 4 presents the discharges of the trade-off solution and the comparison with those from the conventional operation scheme in the same year, where $Q_{\mathrm{r}}$ is the sum of $Q^{t}{ }_{\mathrm{f}}$ and $Q^{t}$. The corresponding values of human interests' satisfaction and flow alterations were compared as well (Table 2).

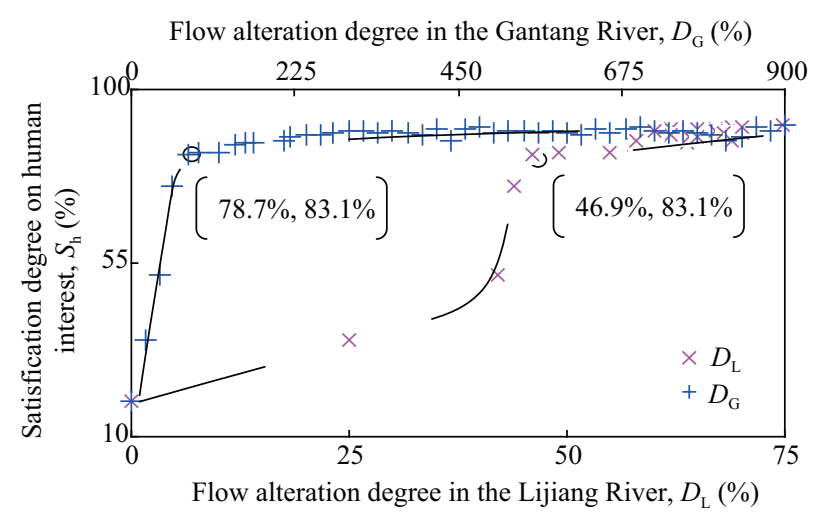

Fig. 3 Flow alteration degrees $\left(D_{\mathrm{G}}\right.$ and $\left.D_{\mathrm{L}}\right)$ in the two rivers and their relations with the overall degree of satisfaction of human interests $\left(S_{\mathrm{h}}\right)$.

Table 2 Comparison of $S_{\mathrm{h}}$ and $D_{\mathrm{f}}$ of the optimal and the conventional operation scheme in typical normal-flow year

\begin{tabular}{lll}
\hline Index & $\begin{array}{l}\text { Under the optimal } \\
\text { operation scheme }\end{array}$ & $\begin{array}{l}\text { Under the conventional } \\
\text { operation scheme }\end{array}$ \\
\hline$S_{\mathrm{h}}$ & $83.1 \%$ & $82.3 \%$ \\
$D_{\mathrm{G}}$ & $78.7 \%$ & $825.7 \%$ \\
$D_{\mathrm{L}}$ & $46.9 \%$ & $66.3 \%$ \\
\hline
\end{tabular}




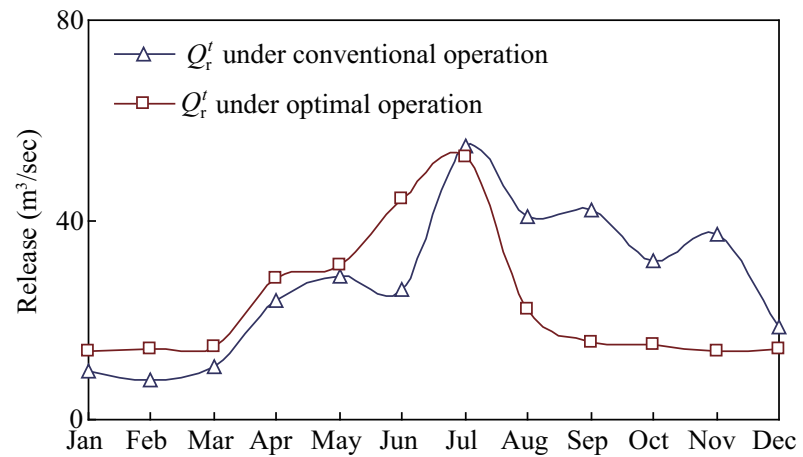

Fig. 4 Comparison of the release under the optimal and the conventional operation schemes in typical normal-flow year.

\section{Discussion}

It is seen from Table 1 that the degree of satisfaction of human interests can reach up to $91 \%$ if the constraint on flow maintenance was excluded, and correspondingly the flow alteration of the Gantang River and the Lijiang River were nearly $900 \%$ and $75 \%$; while in reference (2), the degree of satisfaction of human interests is only $19.4 \%$. The two references reflected the highest conflict between satisfying human interests and maintaining ecosystem flow. Fully conserving the natural flow in the two rivers would greatly benefit the ecosystem while greatly affecting human interests. However, solely considering the human interests in the reservoir operation would cause significant alteration to the river flow, which may seriously affect the biota in the river. Therefore, a compromise must be reached between the two conflicting interests.

Figure 3 indicates that $S_{\mathrm{h}}$ was positively correlated with $D_{\mathrm{G}}$ and $D_{\mathrm{L}}$. For the typical normal-flow year, $D_{\mathrm{G}}$ increased from 0 to around $80 \%$ when $S_{\mathrm{h}}$ rose from $20 \%$ to nearly $83 \%$. Improving $S_{\mathrm{h}}$ from $83 \%$ to $91 \%$ would bring a much sharper increase of flow alteration in the Gantang River, which was nearly $800 \%$. $D_{\mathrm{L}}$ changed with $D_{\mathrm{G}}$, but at a different rate. It increased slowly from $0 \%$ to $40 \%$ when the $S_{\mathrm{h}}$ improved from $20 \%$ to about $55 \%$. However, an additional $3 \%$ increase of $D_{\mathrm{L}}$ brought a $28 \%$ sharp improvement of $S_{\mathrm{h}}$. After this transitional zone, $S_{\mathrm{h}}$ increased slowly again from $83 \%$ to $91 \%$ with $D_{\mathrm{L}}$. Through the relationship, a trade-off solution for reservoir operation was identified, which could overall satisfy $83 \%$ of human interests in irrigation, domestic and navigation water supply. Under the solution, the flow alterations in the Gantang River and the Lijiang River were approximately $80 \%$ and $47 \%$, respectively.

The results in Fig. 4 and Table 2 show that under the conventional operation scheme, the satisfaction degree of human interests was almost $82 \%$, and the flow alterations of the Gantang River and the Lijiang River were nearly $826 \%$ and $66 \%$, respectively. It is seen the optimal solution derived from the proposed approach not only achieved great human interests ( $83 \%$ vs. $82 \%$ ), but also achieved a quasi-natural flow in the rivers, which was important to holistic ecosystem conservation.

The research also found that the alteration in the tribu-

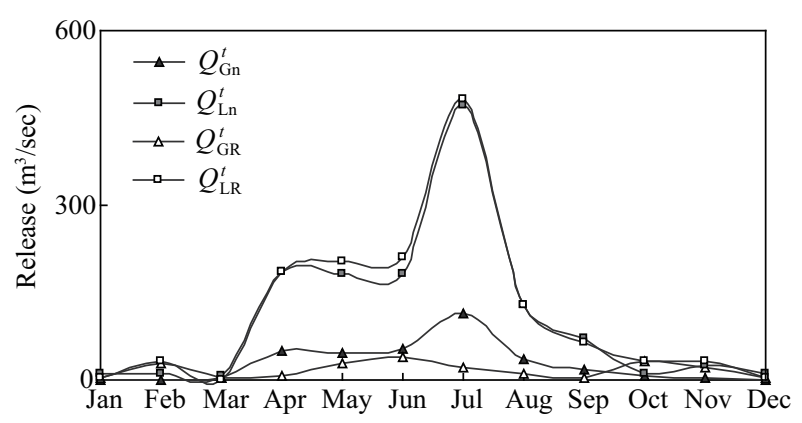

Fig. 5 Flow of the Gantang River and the Lijiang River under reference (1) and their comparison with natural flow regime.

tary (the Gantang River) was much greater than the main stream (the Lijiang River), as shown in Fig. 5. There are two possible reasons: (1) the Qingshitan Reservoir is situated in the Gantang River, thus directly affecting its downstream; and (2) the runoff in the tributary is smaller than the main stream, which resulted in a higher alteration under the same amount of flow modification.

\section{Conclusions}

Maintaining quasi-natural flows in regulated rivers is fundamental to conserve the ecosystem of the rivers, but might affect human demands, especially for some water recreation areas. This study developed an innovative approach to explore adaptive reservoir operations to balance socialeconomic interests and natural flow regime preservation. The essential idea is to use flow alteration degree as a dynamic constraint in the reservoir optimization model so as to pursue a quasi-natural flow. A genetic algorithm was used to seek the compromised model solution that maximized human interests at the cost of an acceptable flow alteration.

The developed method was applied to the Qingshitan Reservoir of the Lijiang River for demonstration. Under the recommended optimal operation scheme, the flow disturbances in the Lijiang River and the Gantang River were approximately $79 \%$ and $47 \%$, respectively. They are much smaller than those under the conventional operation scheme, which caused $826 \%$ and $66 \%$ flow alteration, respectively. However, the satisfactions of human interests under the two operation schemes were nearly the same. This meant that the recommended optimal operation scheme had great advantages for holistic ecosystem protection in comparison with the conventional operation scheme.

The case study indicated that the proposed approach was promising and efficient in optimizing hydraulic structures to operate in an ecological and economical way.

\section{Acknowledgments}

This work was supported by the National Natural Science Foundation of China (No. 50920105907), the National Basic Research Program (973) of (No. 2010CB429004), the 100 Talent Program of Chinese Academy of Sciences (No. A1049) and the Chutian Scholarship (No. KJ2010B002). 


\section{References}

Acreman M, 2000. Managed Flood Releases from Reservoirs: Issues and Guidance. Center for Ecology and Hydrology, UK. http://www.dams.org/docs/kbase/contrib/opt056.pdf.

Akter T, Simonovic S P, 2004. Modelling uncertainties in short term reservoir operation using fuzzy sets and a genetic algorithm. Hydrological Sciences Journal, 49 (6): 10811097.

Cai X M, Mckinney D C, Lasdon L S, 2001. Solving nonlinear water management model using a combined genetic algorithm and linear programming approach. Advances in Water Resources, 24(6): 667-676.

Cardwell H, Jager H I, Sale M J, 1996. Designing instream flows to satisfy fish and hman water needs. Journal of Water Resources Planning and Management, 122(5): 356-363.

Castelletti A, Pianosi F, Soncini-Sessa R, 2008. Water reservoir control under economic, social and environmental constraints. Automatica, 44(6): 1595-1607.

Chang F J, Chen L, 1998. Real-coded genetic algorithm for rulebased flood control reservoir management. Water Resources Management, 12(3): 185-198.

Chen D, Huang G B, Chen Q W, Jin F, 2010. Implementing ecofriendly reservoir operation by using genetic algorithm with dynamic mutation operator. Lecture Notes in Computer Sciences, 6330: 509-516.

Chen Q W, Chen D, Li R N, Ma J F, Blanckaert K, 2012. Adapting the operation of two cascaded reservoirs for ecological flow requirement of a de-watered river channel due to diversion-type hydropower stations. Ecological Modelling. DOI: 10.1016/j.ecolmodel.2012.03.008.

Chen Q W, Yang Q R, Lin Y G, 2011. Development and application of a hybrid model to analyze spatial distribution of macroinvertebrates under flow regulation in the Lijiang River. Ecological Informatics, 6(6): 407-413.

Goldberg D E, 1989. Genetic Algorithms in Search, Optimization and Machine Learning. Addison-Wesley Publishing Co., Inc., Reading MA.

Guangxi Water Resources Bureau, 1984. Surface Water Resources of Guangxi Zhuang Autonomous Region. Guangxi Peoples Press, Guangxi.

Hakimi-Asiabar M, Ghodsypour S H, Kerachian R, 2010. Deriving operating policies for multi-objective reservoir systems: Application of Self-Learning Genetic Algorithm. Applied Soft Computing, 10(4): 1151-1153.

Holland J H, 1975. Adaptation in Natural and Artificial Systems (2nd ed.). Massachusetts Institute of Technology, Cambridge.

Homa E S, Vogel R M, Smith M P, Apse C D, Huber-Lee A, Sieber J, 2005. An optimization approach for balancing human and ecological flow needs. In: EWRI 2005: Impacts of Global Climate Change, Proceedings of the 2005 World Water and Environmental Resources Congress Anchorage, Alaska.

Labadie J W, 2004. Optimal operation of multireservoir systems: state-of-the-art review. Journal of Water Resources
Planning and Management, 130(2): 93-111.

Li R N, Chen Q W, Chen D, 2011a. Ecological hydrograph based on Schizothorax chongi habitat conservation in the dewatered river channel between Jinping cascaded dams. Science China Technological Sciences, 54(S1): 54-63.

Li R N, Chen Q W, Mynett A, Wu S Y, Wang H M, 2008. Modeling of the flow changes due to reservoir operations and the impacts on aquatic ecosystem downstream. Advances in Water Resources and Hydraulic Engineering, VI: 22722278.

Li R N, Chen Q W, Ye F, 2011b. Modelling the impacts of reservoir operations on the downstream riparian vegetation and fish habitats in the Lijiang River. Journal of Hydroinformatics, 13(2): 229-244.

Li W F, Han R, Chen Q W, Qu S, Cheng Z, 2010. Individualbased modelling of fish population dynamics in the river downstream under flow regulation. Ecological Informatics, 5(2): 115-123.

Oliveira R, Loucks D P, 1997. Operating rules for multireservoir systems. Water Resources Research, 33(4): 839-852.

Petts G E, 2009. Instream flow science for sustainable river management. Journal of the American Water Resources Association, 45(5): 1071-1076.

Richter B D, Baumgartner J V, Powell J, Braun D P, 1996. A method for assessing hydrologic alteration within ecosystems. Conservation Biology, 10(4): 1163-1174.

Richter B D, Baumgartner J V, Wigington R, Braun D, 1997. How much water does a river need? Freshwater Biology, 37(1): 231-249.

Schaffer J D, 1984. Some experiments in machine learning using vector evaluated genetic algorithms. Ph.D. Thesis. Vanderbilt University, Nashville, TN.

Sharif M, Wardlaw R, 2000. Multireservoir systems optimization using genetic algorithms: case study. Journal of Computing in Civil Engineering, 14 (4): 255-263.

Smith B T, Jager H I, Sale M J, 2007. Optimization of Hydropower Resources: Current Practices and Opportunities for Improvement. ORNL/TM-2006/91. Oak Ridge National Laboratory.

Srinivas M, Patnaik L M, 1994. Adaptive probabilities of crossover and mutation in genetic algorithms. IEEE Transactions on Systems, Man and Cybernetics, 24(4): 656-667.

Suen J P, Eheart J W, 2006. Reservoir management to balance ecosystem and human needs: Incorporating the paradigm of the ecological flow regime. Water Resources Research, 42: W03417.

Wurbs R A, 1996. Modelling and Analysis of Reservoir System Operation. NJ, Prentice Hall PTR, Prentice-Hall Inc.

Ye F, Chen Q W, Li R N, 2010. Modelling the riparian vegetation evolution due to flow regulation of Lijiang River by unstructured cellular automata. Ecological Informatics, 5(2): 108-114.

Yeh W W G, 1985. Reservoir management and operation models: A state-of-the-art review. Water Resources Research, 121(12): 1797-1818. 